\title{
Study on Indentation Experiments and Mechanical Behavior of RB-SiC
}

\author{
FAN Cheng ${ }^{1, a}$, ZHANG Shijie ${ }^{2}$, ZHAO Qizhi², ZHANG Lei \\ ${ }^{1}$ Jiangsu Provincial Key Labratory of Advanced Robotics \& Collaborative Innovation Center of Suzhou Nano Science and Technology, \\ Soochow University, Suzhou 215021 \\ ${ }^{2}$ College of Mechanical Science and Engineering, Jilin University, Changchun 130025
}

\begin{abstract}
In this work, we studied on the mechanical behavior of RB-SiC by the indentation experiments. The Vickers hardness tester and the laser scanning confocal microscope are used to process and observe the RB-SiC sample pieces. The indentations result shows that the hardness at the $\mathrm{Si}$ phase is lower than the $\mathrm{SiC}$ phase, thus it is easier to remove the $\mathrm{Si}$ than $\mathrm{SiC}$. The morphology of indentations are complicated, there were no accumulation phenomenon at indentation edge. When the loading was $0.1 \mathrm{kgf}, 0.2 \mathrm{kgf}$ and $0.3 \mathrm{kgf}$, only the radical cracking can be observed and the cracking was not obvious at $\mathrm{Si}$ and $\mathrm{SiC}$ mixed phase. Avalanche crushed phenomenon occurred when the load increased to $0.4 \mathrm{kgf}$. According to the Evans' fracture toughness formula, the fracture toughness of SiC phase is about $2.5 \mathrm{MPa} \cdot \mathrm{m}^{1 / 2}$, and the fracture toughness of $\mathrm{Si}-\mathrm{SiC}$ mixed phase is bigger than $3.0 \mathrm{MPa} \cdot \mathrm{m}^{1 / 2}$. The critical cutting depth $\left(d_{c}\right)$ of RB-SiC was calculated by empirical formula presented by T. G. Bifano, and the value is $22.54 \mathrm{~nm}$.
\end{abstract}

\section{Introduction}

RB-SiC have excellent mechanical and chemical properties, such as high hardness, high thermal conductivity, wide band gap etc. Thus, RB-SiC has been considered as one of the most promising materials for lens molds and space telescope mirror [1-3].

Because of the high hardness of the RB-SiC, it is very difficult to remove the material of $\mathrm{RB}-\mathrm{SiC}$. Many methods for processing RB-SiC were presented, such as chemical mechanical polishing [4], electro-chemical mechanical polishing [5] and plasma-assisted polishing [6]. But these methods still may leave damage and scratch on the surface. Thus, it is important to understand the mechanical behavior of $\mathrm{RB}-\mathrm{SiC}$ to realize the ductile material removal. In the previous study, some research of ductile removing of glass materials [7-8] and properties of RB-SiC [9] were studied.

In this work, we studied the properties of $\mathrm{RB}-\mathrm{SiC}$ on Vickers hardness, fracture toughness and critical depth by Vickers indentation experiment. This will help us know more about $\mathrm{RB}-\mathrm{SiC}$ so that we can adjust the processing parameters in the future study.

\section{Vickers indentation experiment}

The size of sample pieces in the experiments is $\Phi 10 \times 8 \mathrm{~mm}$. The sample pieces were preprocessed on the Tegra System Modular sample preparation system (shown in Fig.1). Before processing, the samples were mounted in the epoxy resin as shown in Fig.2. Fig.3 shows the white light interferometer images of the RB$\mathrm{SiC}$ surface morphology. As indicated by Fig.3, RB-SiC consists of two phases, and the distribution of the two phases is not uniform. The 'Island' is the $\mathrm{SiC}$ phase, and the dark part is the Si phase.

Table. 1 is the experiment parameters of the indentation experiments. The Tukon 2500 full automatic Vickers hardness tester (Wilson hardness Ltd.) was used to press on three points on the sample pieces under different loads. The OLS3000 laser scanning confocal microscope (OLYMPUS Ltd.) was used to analyze the indentations.

Table1. Vickers indentation experiments

\begin{tabular}{c|c}
\hline Experiments Conditions & RB-Sic \\
Indenter & Vickers Indenter \\
Load $(\mathrm{kgf})$ & $0.05,0.1,0.2,0.3,0.4$ \\
Loading time(s) & 10 \\
Holding time(s) & 15 \\
Discharging time(s) & 10 \\
\hline
\end{tabular}

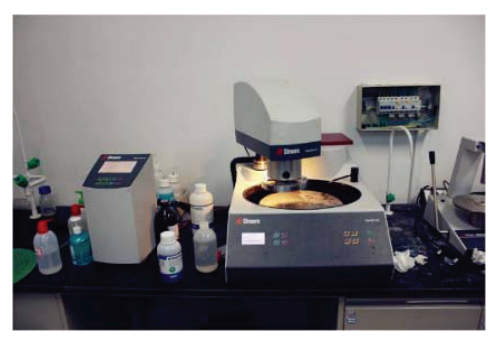

Figure.1 Tegra System Modular sample preparation system

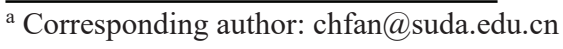




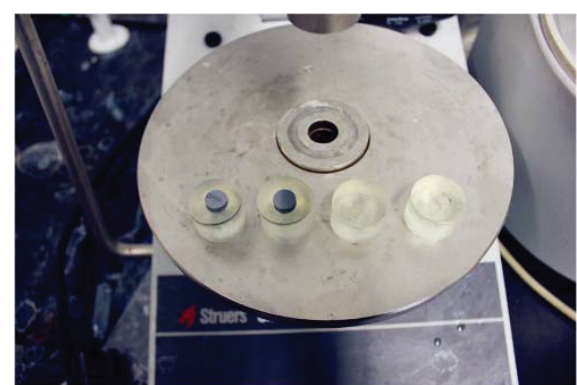

Figure.2 Samples mounted in the epoxy resin

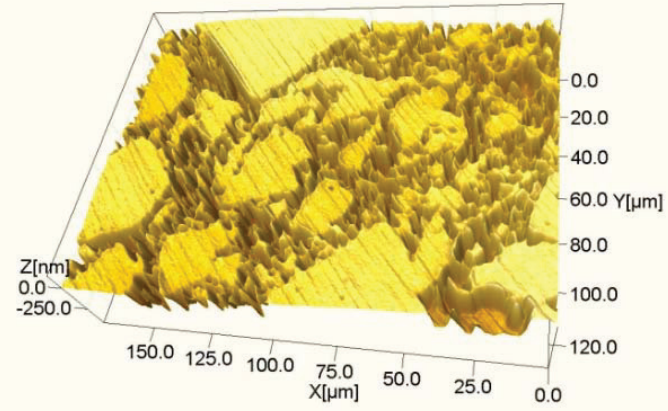

Figure.3 White light interferometer images of the RB-SiC surface morphology

\section{Vickers indentation experiment}

\subsection{Analysis of Vickers hardness}

Four arrises vertebral diamond was used as indenter in the Vickers hardness experiments. The Vickers hardness can be obtained by:

$$
H V=\frac{F}{S}=\frac{2 F \sin 68^{\circ}}{d^{2}}=1.854 \frac{F}{d^{2}}
$$

where $H V$ is the Vickers hardness $\left(\mathrm{kgf} / \mathrm{mm}^{2}\right), F$ is the load, $(\mathrm{kgf}), S$ is the area of the indentation $\left(\mathrm{mm}^{2}\right)$, and $d$ is the average length of diagonal of the indentation.

Table. 2 shows the Vickers hardness of RB-SiC under different loads. According to Table 2, there is no size effect between the Vickers hardness and the load. Because there are two phases exist in RB-Si and the distribution and size of two phases are not uniform, the indenter contact different phases at each time.

Table 2. Hardness of RB-SiC under different load

\begin{tabular}{cc}
\hline $\operatorname{Load}(\mathrm{kgf})$ & $\bar{H}(\mathrm{Gpa})$ \\
\hline 0.05 & 19.054 \\
0.1 & 23.232 \\
0.2 & 19.515 \\
0.3 & 25.350 \\
0.4 & 20.636 \\
\hline
\end{tabular}

For the indentation load of $0.2 \mathrm{~kg}$, the contact area and the Vickers hardness are shown in Fig.4 and Table. 3 respectively. In Fig.4(a) and (b), the indenter was pressed on the SiC phase, thus the Vickers hardness is similar as indicated in Table.3. In Fig.4(c), the indenter was pressed on the mixed phase where the particle size of $\mathrm{SiC}$ is small. Thus, the Vickers hardness is lower than SiC phase. We can infer that the Vickers hardness of $\mathrm{Si}$ is much lower than $\mathrm{SiC}$. In Fig.4(d), the indentation was almost pressed on $\mathrm{SiC}$ phase, thus the Vickers hardness is similar to pure $\mathrm{SiC}$ phase.

According to the analysis above, when grinding or polishing $\mathrm{RB}-\mathrm{SiC}$, the $\mathrm{Si}$ phase can be removed easier than the $\mathrm{SiC}$ phase. As a result the 'step' structure appeared. It is quite hard to obtain high surface quality of $\mathrm{RB}-\mathrm{SiC}$

Table.3 The Vickers hardness of different contact area under $0.2 \mathrm{~kg} f$

\begin{tabular}{ccc}
\hline Contact area & $H(\mathrm{Gpa})$ & The corresponding figure \\
\hline SiC phase & 27.243 & Fig.4a \\
SiC phase & 27.410 & Fig.4b \\
Mixed phase of Si and $\mathrm{SiC}$ & 16.465 & Fig.4c \\
Mixed phase of Si and $\mathrm{SiC}$ & 24.213 & Fig.4d \\
(SiC phase over a half) & & \\
\hline
\end{tabular}

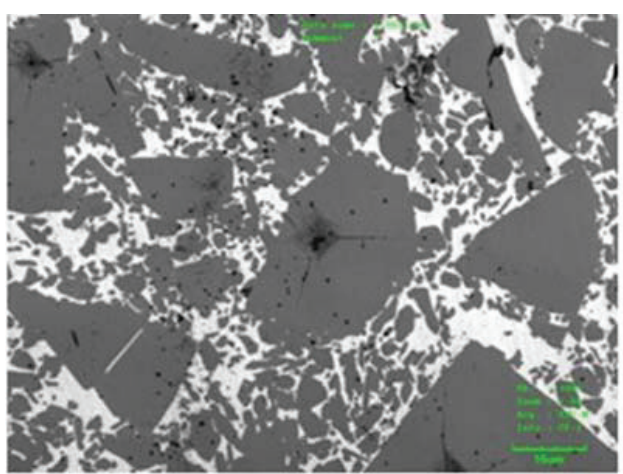

(a)

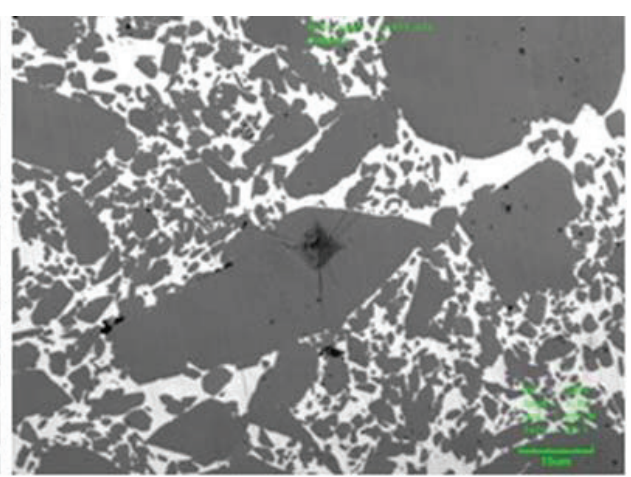

(b) 


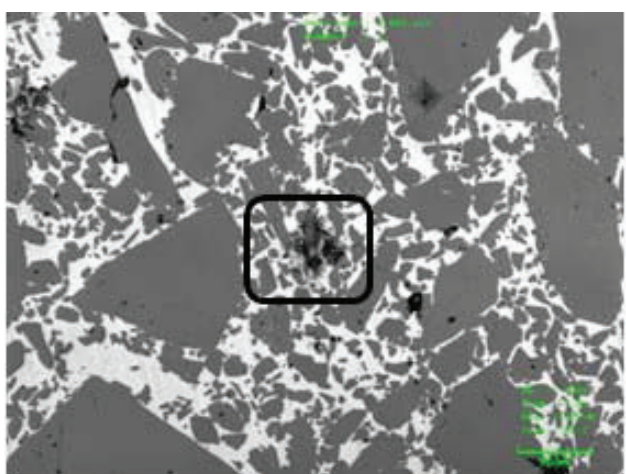

(c)

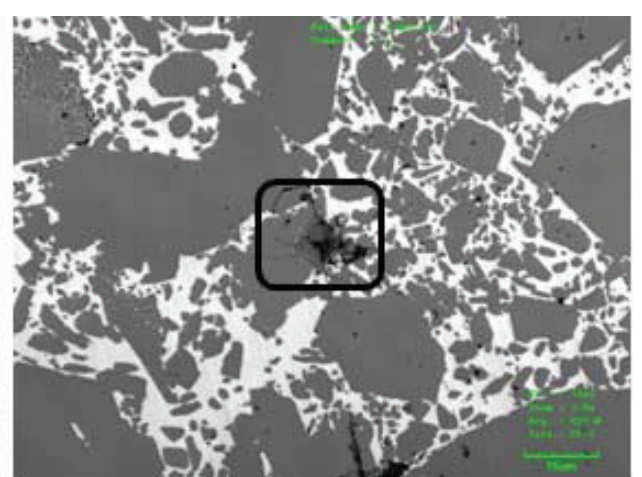

(d)

Figure.4 The morphology of indentation under $0.2 \mathrm{~kg} f$

\subsection{Analysis of the morphology of indentations}

The general cracks of the Vickers indentation are shown in Fig.5. There are two radial cracks along the extension cord of rectangular indentation diagonal lines as shown in Fig.5(a).As shown in Fig.5(b), two radical cracks and median crack make half-penny crack. In general, halfpenny crack system is considered as half round, but the reality is different from the ideal, especially under the low load. Fig.5(c) shows the radical cracks in a separate form observed from the cross section.

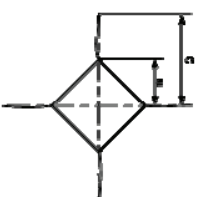

(a)

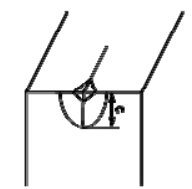

(b)

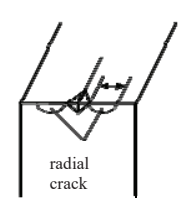

(c)
Fig.6 shows the morphology of the indentation under different loads. The morphology is complicated, black area is the $\mathrm{SiC}$ phase, the white area is the the Si phase, and the distribution of two phases are not uniform. Under the low load $(0.05 \mathrm{kgf})$, only plastic deformation occurred. With the increasing of loads ( $0.1 \mathrm{kgf}, 0.2 \mathrm{kgf}$ and $0.3 \mathrm{kgf}$ ), there were obvious radical cracks at the diagonal of indentation of the $\mathrm{SiC}$ phase, but the cracks at the $\mathrm{Si}$ and $\mathrm{SiC}$ mixed phase were shorter. No material accumulation appeared at the edges of the indentation on the mixed phase. When load increased to $0.4 \mathrm{kgf}$, radical cracks could be clearly seen at the diagonal of indentation. In addition, a 'shell' like mass breakage occurred which is shown in Fig.6e. Because of the heavy load, the lateral cracks spread from subsurface to surface which results in the fall off of SiC.

Figure.5 Schematic of Vickers indentation
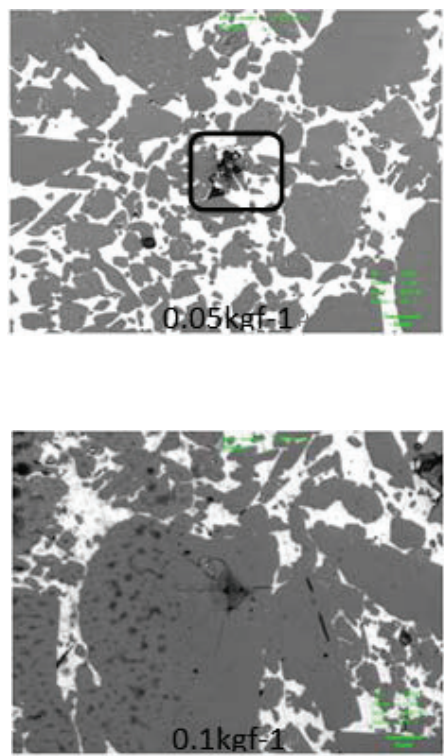
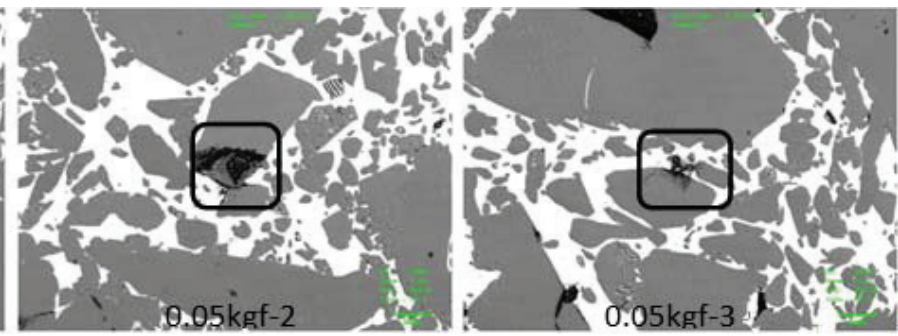

(a)

$0.05 \mathrm{kgf}$
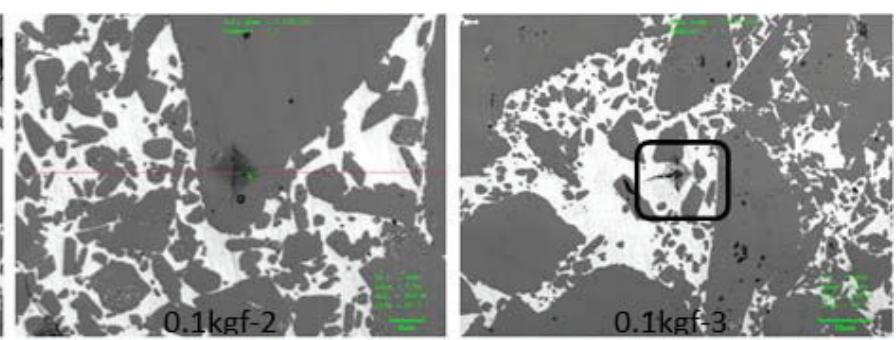

(b) $0.1 \mathrm{kgf}$ 

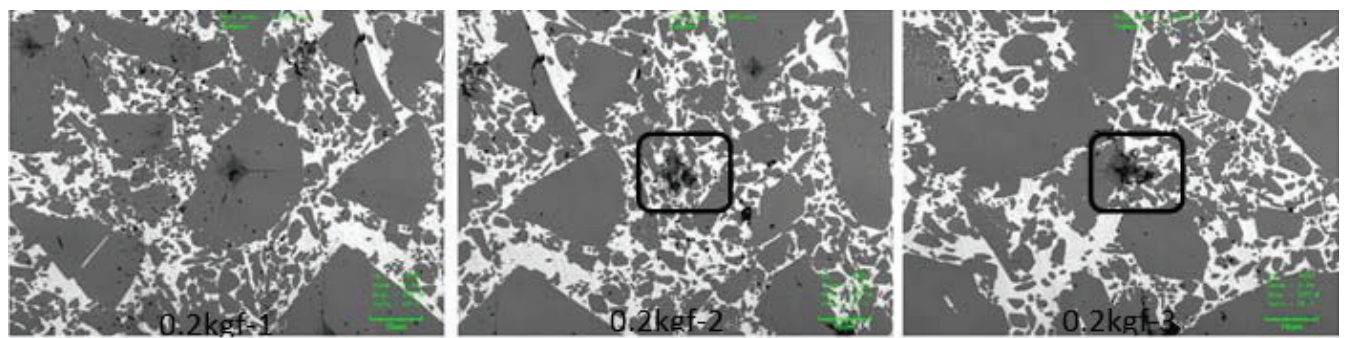

(c) $0.2 \mathrm{kgf}$
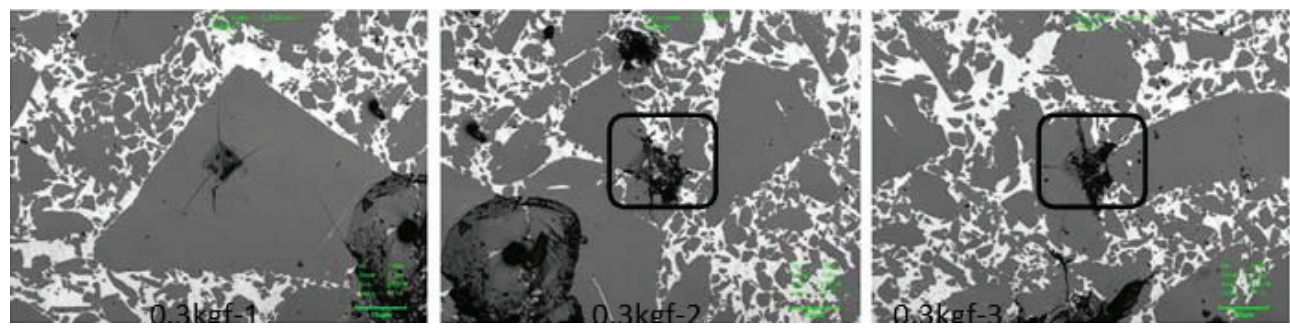

(d) $0.3 \mathrm{kgf}$

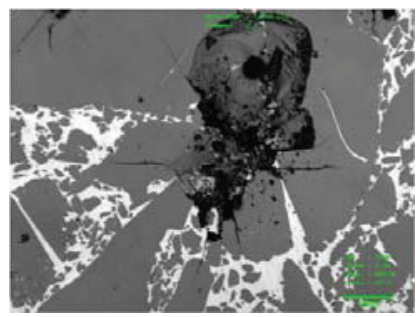

(e) $0.4 \mathrm{kgf}$

Figure.6 The morphology of indentation of RB-Si

\section{Fracture toughness of the indentation}

The calculation of the indentation fracture toughness is mainly based on two different crack systems, one is Half - Penny Crack System, also known as the Median/Radial Crack System and the other is Palmqvist cracks System. But for RB-SiC, since its Vickers indentation cracks are complicated, it is hard to define the system it belongs to. Since the RB-SiC is a typical polycrystalline ceramic materials. Therefore, the fracture toughness formula of RB-SiC $\left(K_{I C}\right)$ can be calculated by the equation of the fracture toughness presented by Evans[10], which gives:

$$
\left(\frac{K_{I C}}{H \sqrt{a}}\right)\left(\frac{H}{E}\right)^{0.4}=10^{y}
$$

where

$$
y=-1.59-0.34 x-2.02 x^{2}+11.23 x^{3}-24.97 x^{4}+15.32 x^{5}
$$

and

$$
10^{x}=\frac{c}{a}
$$

In $\mathrm{Eq}(2), E$ is the elastic modulus of the material, $H$ is the hardness, $c$ is the half length of the crack, and $a$ is the half length of the diagonal of the indentation. According to Eq.(2), (3) and (4), the fracture toughness is calculated and the results are shown in Table.4.

The fracture toughness of $\mathrm{SiC}$ phase is about $2.5 \mathrm{MPa} \cdot \mathrm{m}^{1 / 2}$, the fracture toughness of mixed phase is larger than $3.0 \mathrm{MPa} \cdot \mathrm{m}^{1 / 2}$.

\section{Critical depth $d_{c}$}

It is necessary to calculate the critical depth so that the hard brittle material can be removed (grinding) ductile under this depth and left no cracks and damage [8-9]. T. G. Bifano[8], presented the critical depth model of the glass material by the indentation method based on the Griffith crack extension criterion, which gives:

$$
d_{c}=a\left(\frac{E}{H_{v}}\right)\left(\frac{K_{I C}}{H_{v}}\right)^{2}
$$

where $a$ is a constant of system, $E$ is the elastic modulus of the material, $H_{v}$ is the hardness of the material, and $K_{I C}$ is the fracture toughness of the material. The scanning 
Table.4 The fracture toughness of $\mathrm{RB}-\mathrm{SiC}$ under different load

\begin{tabular}{|c|c|c|c|c|}
\hline Load(kgf) & Contact area & $H(\mathrm{Gpa})$ & Length of $\operatorname{crack}(\mu m)$ & $K_{I C}\left(\mathrm{MPa} \cdot \mathrm{m}^{1 / 2}\right)$ \\
\hline \multirow{3}{*}{0.1} & SiC phase & 24.94 & 8.812 & 2.606 \\
\hline & Si phase & 26.37 & 9.669 & 2.434 \\
\hline & $\mathrm{SiC}$ phase & 18.39 & 8.111 & 2.657 \\
\hline \multirow{3}{*}{0.2} & SiC phase & 27.24 & 14.527 & 2.729 \\
\hline & SiC phase & 27.41 & 16.616 & 2.327 \\
\hline & Mixed phase & 24.21 & 12.771 & 3.048 \\
\hline \multirow{3}{*}{0.3} & SiC phase & 25.97 & 22.903 & 2.205 \\
\hline & Mixed phase & 25.17 & 15.564 & 3.387 \\
\hline & Mixed phase & 24.92 & 17.855 & 3.045 \\
\hline \multicolumn{5}{|c|}{ Table.5 The critical depth of RB-SiC under different load } \\
\hline Load(kgf) & Contact area & $H(\mathrm{Gpa})$ & $K_{I C}\left(\mathrm{MPa} \cdot \mathrm{m}^{1 / 2}\right)$ & $d_{c}(\mathrm{~nm})$ \\
\hline \multirow{3}{*}{0.1} & SiC phase & 24.94 & 2.606 & 21.67 \\
\hline & Si phase & 26.37 & 2.434 & 15.99 \\
\hline & $\mathrm{SiC}$ phase & 18.39 & 2.657 & 56.19 \\
\hline \multirow{3}{*}{0.2} & $\mathrm{SiC}$ phase & 27.24 & 2.729 & 18.24 \\
\hline & SiC phase & 27.41 & 2.327 & 13.02 \\
\hline & Mixed phase & 24.21 & 3.048 & 32.41 \\
\hline \multirow{3}{*}{0.3} & SiC phase & 25.97 & 2.205 & 13.74 \\
\hline & Mixed phase & 25.17 & 3.387 & 35.61 \\
\hline & Mixed phase & 24.92 & 3.045 & 29.66 \\
\hline
\end{tabular}

electron microscope is used to observe the surface, and the critical depth empirical is shown in $\operatorname{Eq}(6)$ when the crack of indentation surface is less than $10 \%$.

$$
d_{c}=0.15\left(\frac{E}{H_{v}}\right)\left(\frac{K_{I C}}{H_{v}}\right)^{2}
$$

After calculation, the critical depth of $\mathrm{RB}-\mathrm{SiC}$ is shown in Table.5.

\section{Conclusions}

(1) The morphology of RB-SiC is complicated. No material accumulation appeared at the edge of the mixed phase indentation. When the load is $0.1 \mathrm{kgf}, 0.2 \mathrm{kgf}$ and $0.3 \mathrm{kgf}$, the radical cracks appeared at $\mathrm{SiC}$ phase. When the load is $0.4 \mathrm{kgf}$, the massive avalanche crushed phenomenon appeared.

(2) The modulus presented by Evans was used to calculate the fracture toughness under different load. The fracture toughness of $\mathrm{SiC}$ phase is about $2.5 \mathrm{MPa} \cdot \mathrm{m}^{1 / 2}$, the fracture toughness of mixed phase is larger than $3.0 \mathrm{MPa} \cdot \mathrm{m}^{1 / 2}$

(3) The critical depth of ductile-brittle translation of $\mathrm{RB}-\mathrm{SiC}$ is $22.54 \mathrm{~nm}$ on average.

\section{Acknowledgement}

This work is supported by the Chinese National Natural Science Foundation under Grant 51505312, the Basic Research Program of Jiangsu Province under Grant BK20150330, the Chinese Postdoctoral Science Foundation under Grant 2015M571800 and National Natural Science Foundation of China under Grant 61503268.

\section{References}

1. Lee H Y, Kim D W, Sung Y J, et al. Fabrication of SiC micro-lens by plasma etching[J]. Thin Solid Films, 475(1-2):318-322.(2005)

2. Pang $\mathrm{S}$ W, Tamamura $\mathrm{T}$, Nakao $\mathrm{M}$, et al. Direct nano-printing on $\mathrm{Al}$ substrate using a $\mathrm{SiC}$ mold[J]. Journal of Vacuum Science \& Technology B Microelectronics \& Nanometer Structures, 16(3):1145-1149.(1998)

3. Ebizuka N, Eto H, Dai Y, et al. SiC ultralight mirror for large space telescope and for extremely huge ground-based telescope II[J]. Proceedings of SPIE The International Society for Optical Engineering, 5487:329-334.(2004)

4. Zhou L, Audurier V, Pirouz P, Powell JA (1997) Chemomechanical Polishing ofSilicon Carbide. Journal of the Electrochemical Society 144(6):L161L163.

5. Deng H, Hosoya $\mathrm{K}$, Imanishi $\mathrm{Y}$, et al. Electrochemical mechanical polishing of single-crystal $\mathrm{SiC}$ using $\mathrm{CeO}$ 2, slurry[J]. Electrochemistry Communications, 52:5-8.(2015)

6. Yamamura $\mathrm{K}$, Takiguchi $\mathrm{T}$, Ueda $\mathrm{M}$, et al. Plasma assisted polishing of single crystal $\mathrm{SiC}$ for obtaining atomically flat strain-free surface[J]. CIRP Annals - Manufacturing Technology, 60(1):571574.(2011)

7. Xiang Y, Chen J, Bai M S, et al. Experimental study of brittle-ductile translation critical condition in Li2O-A12O3-SiO2 glass-ceramic machining[J]. Journal of Applied Optics, (2014).

8. Bifano T G, Dow T A, Scattergood R O. DuctileRegime Grinding: A New Technology for Machining Brittle Materials[J]. Journal of Engineering for Industry, 113(2):184-189.(1991)

9. Zhang J, Jiang D, Lin Q, et al. Properties of silicon carbide ceramics from gelcasting and pressureless 
sintering[J]. Materials \& Design (1980-2015), 65(20):12-16.(2013)

10. Evans A G, Charles E A. Fracture Toughness

Determination by Indentation[J]. Journal of the American Ceramic Society, 59(7-8):371-372.(2006) 